\title{
Crisis y posibilidades de activación socioeconómica de las zonas deprimidas de la provincia de León
}

\author{
Ana Fe Astorga González
}

\section{MONTAÑA LEONESA: UNA ECONOMIA RURAL EN CRISIS}

La provincia de León se muestra como una tierra de contrastes, donde marcadas diferencias morfoestructurales (zonas montañosas, tierras Ilanas, depresiones, riberas y amplios valles) se corresponden con importantes discordancias socio-económicas y culturales.

De los $15.468 \mathrm{~km}^{2}$ de superficie provincial, $3.980,6 \mathrm{~km}^{2}$ pertenecerian a áreas declaradas de "Acción Especial». Se trata de cinco comarcas agrarias con estructuras arcaicas, afectadas de una grave crisis involutiva, que suman el 25,7\% del territorio: Bierzo Oeste, Cabrera. Maragateria-Cepeda, Omaña y Hiaño (fig. 1).

Los procesos de cambio, que germinaron en la sociedad y economía rural desde la década de los sesenta, han dado origen en estas zonas de equilibrio precario a serios desajustes que alteraron su frágil estabilidad (combinación del arcaísmo y la innovación). Se han consolidado transformaciones demográficas, regresiones económicas, desaparición de actividades alternativas a la agricultura, etc.

Desde el punto de vista biofísico, aparecen afinidades derivadas de la singular articulación del relieve, el clima y la vegetación; las duras condiciones impuestas han tenido una patente manifestación en la ocupación del suelo, pues suponen una de las más graves dificultades con las que han de enfrentarse los pobladores de estas comarcas a la hora de extraer beneficios de la explotación de sus tierras. Socioeconómicamente

(*) Becaria del Departamento de Geografia e Historia de las Instituciones Económicas. Uni. versidad de León. 


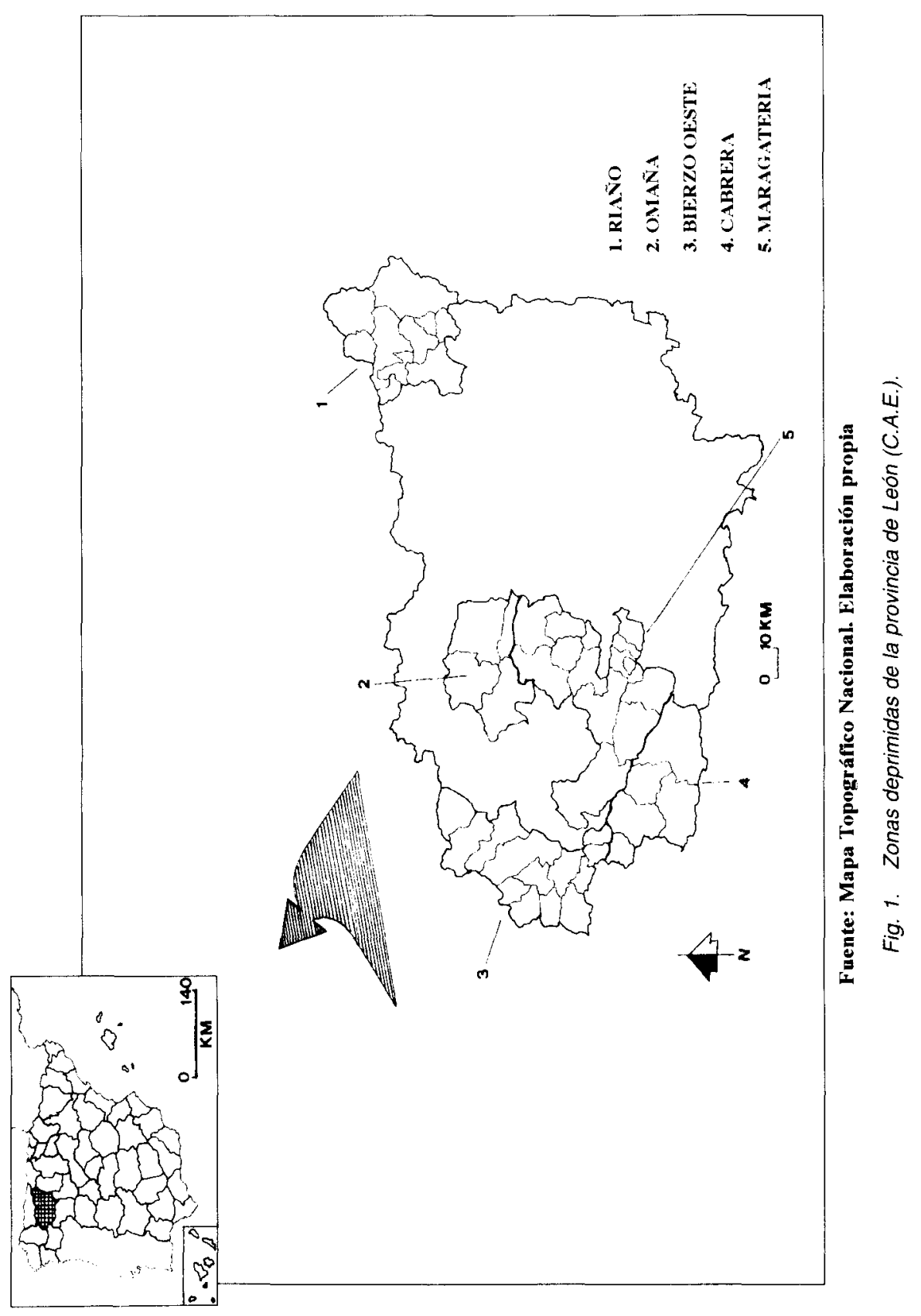


se caracterizan por una densidad de población y niveles de renta inferiores a la media nacional (LÓPEZ FERNÁNDEZ, B., 1983).

La base económica es la agricultura de autoconsumo ejercida sobre terrenos poco aptos con unas técnicas y aperos ancestrales, a lo que se suma una estructura de la propiedad compuesta de explotaciones resultantes de la yuxtaposición de pequeñas parcelas diseminadas. Esta fragilidad nace de la inconsistencia de los recursos disponibles, a la que hay que añadir las graves consecuencias de los impactos derivados de actuaciones externas (Astorga GonzÁlez, A. F., 1993).

Siglos de aislamiento físico, económico y social, han conducido a un preocupante despoblamiento, donde la estructura interna de la población, consecuencia de un éxodo masivo, refleja escasa natalidad, ausencia de estratos activos (grupos de edad entre 19 y 45 años) y notable envejecimiento. Así, los núcleos se encontrarían en un estado de infrapoblación y semiabandono con todo el deterioro urbanístico que esto conlleva (LóPEZ FERNÁNDEZ, B., 1986).

Las dificultades de acceso desde el punto de vista de las comunicaciones tanto interregionales como intrarregionales y el grado de dispersión de los pequeños núcleos de población son otras de las limitaciones que entorpecen la infiltración de estas áreas en la dinámica del desarrollo. Las inversiones se encarecen y los déficits de equipamientos mínimos que padecen los habitantes no se corrigen (M.A.P.A., 1988).

Los territorios de montaña aglutinan la mayor parte de las "Comarcas Deprimidas" de la provincia; de hecho, existe cierta asociación de ideas entre lo montañés y la pervivencia de gentes atrasadas encerradas en unas formas de vida regidas por condicionantes ancestrales. Los largos periodos de “incomunicación" han dado lugar a la aparición de una subcultura que, paradójicamente, hoy está en trance de extinción (Caro Baroja, J., 1985).

Con el término "deprimido" aplicado a espacios geográficos, haremos referencia a estas áreas que, además de alejamiento físico y socio-económico, presentan cierta situación de abandono por parte de la Administración. La marginalidad es reflejo de un nivel inferior, efecto del aislamiento espacial, los insuficientes recursos, la baja productividad y las trabas que impone la acción humana en cuanto a la gestión y ordenación.

A pesar de presentar rasgos comunes, reflejo de los mecanismos de adaptación humana para paliar los factores adversos que allí se combinan, entre ellas existen diferencias (tabla 1), si bien las disparidades no 
se desvían netamente de los valores promedio hallados para el conjunto de las C.A.E. '.

En este contexto someramente descrito centraremos el estudio, orientado a analizar la situación de estas zonas, intentando explicar y articular soluciones alternativas, diversas para cada región. Es necesario abandonar interpretaciones monistas, pues si bien es cierto que hay temas comunes, como son la conservación del medio ambiente, los usos del suelo de acuerdo a las potencialidades, la recuperación demográfica, etc., sin embargo, debemos diseñar para cada zona un modelo particular de recuperación.

\section{EL PERFIL DEMOGRÁFICO}

\subsection{Diagnóstico de la población y su dinámica}

La disimétrica evolución demográfica del conjunto geográfico provincial, a la que sin duda podríamos calificar de preocupante, llega a su

Una Comarca de Acción Especial estaria constituida por un conjunto más o menos homogéneo de términos municipales cuyas características socio-demográficas ("renta per cápita", demografía, infraestructuras, equipamientos, presupuestos municipales...) describen una serie de carencias que entran dentro de los límites establecidos por el Real Decreto $3.418 / 1978$ como criterios de selección de las "Comarcas de Acción Especial». La primera C.A.E. declarada como tal por un acuerdo del Consejo de Ministros fue la de Riaño el 18 de febrero de 1972. Incluye a diez municipios y 58 entidades menores situados en el Noreste de la provincia. El 6 de marzo de 1986 se reconoció este espacio como "Zona de Agricultura de Montaña»; sin embargo, aún hoy no se ha realizado ninguno de los programas previstos por la C.E.

Esta misma zona, a tenor de la Ley 8/1989, de 9 de noviembre, de Regulación Transitoria del Fondo de Compensación Regional, fue seleccionada por la Excma. Diputación Provincial de León como "Área Desfavorecida", recibiendo a partir de ese momento las subvenciones destinadas a desagraviar su precaria situación y sentar así las bases para un desarrollo socioeconómico a partir de los recursos y las actividades tradicionales de la zona.

En 1979 se declararon Comarcas de Acción Especial La Cabrera (6 de junio), con 5 municipios y 52 núcleos de población, y El Bierzo Oeste (11 de octubre) que agrupó 13 municipios y 145 entidades. Ambas C.A.E. se encuentran situadas en el extremo Oeste de la provincia, en un entorno montañoso de difícil acceso.

La mayor parte de la C.A.E. denominada «Bierzo Oeste» (Los Ancares y otros pequeños valles próximos) en función del Decreto 43/1986, de 6 de marzo, del Ministerio de Agricultura, podría entrar en la categoría de "Zona de Agricultura de Montaña"; no obstante, las gestiones se encuentran paralizadas.

El 6 de junio de 1980 se declaró C.A.E. a la zona leonesa de La Omaña, con tres municipios y 59 entidades menores. Más tarde, en 1987 se incorporó a ella el municipio de Igüeña que, aunque espacialmente es colindante con esta zona, tiene una base económica minera y una vinculación cultural al Bierzo.

Actualmente la C.A.E. de Omaña incluye a 67 núcleos de población.

Maragateria-Cepeda, amplia zona que aglutina a 13 municipios y 108 pueblos de zonas aparentemente tan dispares como la Somoza, la Sequeda y la Cepeda, fue reconocida como zona desfavorecida y por tanto declarada C.A.E. el 20 de junio de 1984 (Excma. Diputación Provincial de León, 1992). 
máxima expresión en estas unidades espaciales donde los perfiles poblacionales se muestran muy críticos en contraste con otras comarcas vecinas donde la población se concentra (Alonso SANTOS, L., y CABERO DIÉGUez, V., 1982).

Durante los últimos veinticinco o treinta años, estas zonas han asistido a una constante pérdida de sus fuerzas vitales y activas, con retrocesos superiores al $50 \%$ e incluso hasta más del $60 \%$, lo que supone la instauración de una dinámica regresiva. El despoblamiento ha sido una consecuencia del paso de un modelo frágil y tradicional de ocupación-explotación de los recursos en las zonas agrarias de montaña a un nuevo modelo, es decir, surge como manifestación de las dificultades que impone el medio físico conjugadas con la reestructuración de las actividades económicas.

TABLA 1. MUNICIPIOS, ENTIDADES, SUPERFICIE DE LAS C.A.E.

\begin{tabular}{|c|c|c|c|c|c|}
\hline & MUNICIPIOS & $\begin{array}{c}N^{\circ}= \\
\text { ENTIDADES }\end{array}$ & $\begin{array}{c}\text { SUPERF. } \\
\text { S } \\
\left(K M^{2}\right)\end{array}$ & $\begin{array}{l}\text { HAB. } \\
1991\end{array}$ & $\mathrm{H} / \mathrm{km}^{2}$ \\
\hline \multirow[t]{14}{*}{ MARAGAT.-CEP.: } & Brazuelo & 9 & 98,2 & 355 & 3,6 \\
\hline & Lucillo & 8 & 164,0 & 521 & 3,1 \\
\hline & Luyego de $S$. & 6 & 134,9 & 990 & 7,3 \\
\hline & Magaz de C. & 6 & 72,4 & 552 & 7,6 \\
\hline & Molinaseca & 7 & 79,4 & 744 & 9,3 \\
\hline & Quintana del C. & 13 & 155,2 & 1.134 & 7,3 \\
\hline & Sta.Colomba de S. & 17 & 179,4 & 486 & 2,7 \\
\hline & Santiago Millas & 5 & 39,9 & 364 & 9,1 \\
\hline & Valderrey & 9 & 60,5 & 772 & 12,7 \\
\hline & Val de S.Lorenzo & 3 & 49,9 & 830 & 16,6 \\
\hline & Villagatón & 12 & 167,6 & 905 & 5,3 \\
\hline & Villamejil & 7 & 79,3 & 1.091 & 13,7 \\
\hline & Villaobispo de $\mathrm{O}$ & 6 & 31,9 & 768 & 24,0 \\
\hline & Total & 108 & $1.312,4$ & 9.472 & 7,2 \\
\hline \multirow[t]{7}{*}{ RIAÑO: } & Acebedo & 3 & 50,5 & 416 & 8,2 \\
\hline & Boca de $\mathrm{H}$. & 9 & 245,8 & 724 & 2,9 \\
\hline & Burón & 7 & 159,3 & 537 & 3,3 \\
\hline & Crémenes & 15 & 152,5 & 1.567 & 10,2 \\
\hline & Maraña & 1 & 33,7 & 198 & 5,8 \\
\hline & Oseja de S. & 5 & 81,5 & 345 & 4,2 \\
\hline & Pedrosa del R. & 2 & 28,4 & 0 & 0,0 \\
\hline
\end{tabular}


TABLA 1. MUNICIPIOS, ENTIDADES, SUPERFICIE DE LAS C.A.E. (continuación)

\begin{tabular}{|c|c|c|c|c|c|}
\hline & MUNICIPIOS & $\begin{array}{c}\text { № } \\
\text { ENTIDADES }\end{array}$ & 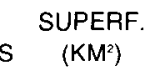 & $\begin{array}{l}\text { HAB. } \\
1991\end{array}$ & $\mathrm{H} / \mathrm{km}^{2}$ \\
\hline & Posada de V. & 8 & 165,6 & 496 & 2,9 \\
\hline & Prioro & 2 & 49,2 & 562 & 11,4 \\
\hline & Riaño & 6 & 81,1 & 485 & 5,9 \\
\hline & Total & 58 & $1.046,6$ & 5.319 & 5,0 \\
\hline \multirow[t]{5}{*}{ OMAÑA: } & Igüeña & 8 & 207,8 & 2.462 & 11,8 \\
\hline & Murias de P. & 15 & 95,7 & 786 & 8,2 \\
\hline & Riello & 39 & 236,7 & 1.186 & 5,0 \\
\hline & Valdesamario & 5 & 62,1 & 369 & 5,9 \\
\hline & Total & 67 & 602,3 & 4.799 & 7,9 \\
\hline \multirow[t]{6}{*}{ CABRERA: } & Benuza & 17 & 174,6 & 783 & 4,4 \\
\hline & Castrillo de C. & 6 & 114,7 & 281 & 2,4 \\
\hline & Encinedo & 9 & 191,9 & 948 & 4,9 \\
\hline & Puente de D. F. & 7 & 58,9 & 1.994 & 33,8 \\
\hline & Truchas & 13 & 303,0 & 1.017 & 3,3 \\
\hline & Total & 52 & 844,0 & 5.024 & 5,9 \\
\hline \multirow[t]{14}{*}{ BIERZO OESTE: } & Balboa & 17 & 52,2 & 554 & 10,6 \\
\hline & Barjas & 14 & 57,9 & 608 & 10,5 \\
\hline & Borrenes & 5 & 33,0 & 606 & 18,3 \\
\hline & Candín & 11 & 207,0 & 495 & 2,3 \\
\hline & Carucedo & 7 & 35,0 & 704 & 20,1 \\
\hline & Corullón & 8 & 81,9 & 1.496 & 18,2 \\
\hline & Oencia & 9 & 88,8 & 525 & 5,9 \\
\hline & Peranzanes & 7 & 109,7 & 379 & 3,4 \\
\hline & Sobrado & 8 & 44,6 & 614 & 13,7 \\
\hline & Trabadelo & 10 & 70,4 & 637 & 9,0 \\
\hline & Vega de $E$. & 11 & 132,6 & 3.270 & 24,6 \\
\hline & Vega de V. & 22 & 70,2 & 1.141 & 16,2 \\
\hline & Villafranca del B. & 16 & 182,1 & 4.136 & 22,7 \\
\hline & Total & 145 & $1.175,3$ & 15.090 & 12,8 \\
\hline
\end{tabular}

Fuente: Excma. Diputación Provincial de León. Elaboración propia.

La regresión seguida entre los períodos intercensales de 1950 a 1991 por todas las C.A.E. tan sólo ha sido superada en algunos momentos 
puntuales por algún municipio, si bien las ganancias siempre han resultado inferiores al $5 \%$ de la población? ${ }^{2}$.

La precaria situación económica de estas zonas, unida a la atracción ejercida por el factor industrial y urbano ${ }^{3}$, explica las pérdidas poblacionales (tabla 2). La sangría de recursos humanos es el testimonio más fiel de la subordinación de las áreas deprimidas a las zonas urbanas o industrializadas que han tenido aquí su más importante reserva de mano de obra (GARCiA ZaRZA, E., 1983).

\section{TABLA 2. EVOLUCIÓN DE LA POBLACIÓN DE HECHO POR COMARCAS}

\begin{tabular}{lrrrrr}
\hline \multicolumn{1}{c}{ COMARCAS } & 1900 & 1950 & 1986 & 1991 & $\begin{array}{c}\text { \% PÉRDIDA } \\
\text { DESDE 1950 }\end{array}$ \\
\hline Cabrera & 11.209 & 11.388 & 5.762 & 5.024 & 55,9 \\
Riaño & 12.593 & 12.914 & 6.054 & 5.319 & 58,9 \\
Bierzo O. & 33.382 & 34.178 & 17.884 & 15.090 & 55,9 \\
Marag.-Cep. & 25.941 & 25.254 & 10.992 & 9.472 & 62,5 \\
Omaña & 10.776 & 9.612 & 5.359 & 4.799 & 50,1 \\
\hline Total & 93.901 & 93.346 & 46.051 & 39.704 & 57,5 \\
\hline
\end{tabular}

Fuente: I.N.E. Censos y Padrones Municipales. Elaboración propia.

El trasvase de población era necesario ${ }^{4}$, pero la intensidad de la sangría ha llevado a una ruptura del equilibrio demográfico, ya de por si tendente a la despoblación (González González, Mà. J. et al., 1986).

2 Bierzo Oeste perdió el $55,9 \%$ de su población. A nivel municipal fueron Candin $(75,1 \%), \mathrm{Pe}$ ranzanes $(72,4 \%)$, Oencia $(67 \%)$, Barjas $(66,3 \%)$ y Corullón $(60,9 \%)$ los que más bajas experimentaron. La nota dominante en Maragatería-Cepeda es el descenso demográfico sufrido a partir de la década 1950-1960, fecha en la que se alcanzó la cota máxima. Los municipios que más acusaron esta situación fueron Santa Coloma de Somoza $(76,6 \%)$ y Brazuelo $(76,4 \%)$. Omaña sufre igualmente un proceso regresivo a partir de 1950, contando en la actualidad con 5.975 habitantes menos que en 1900. También las C.A.E. de Riaño y Cabrera pierden población, pero de forma aún más acusada, lo cual se debe en el primer caso al proyecto y realización del embalse. La Cabrera, al contrario que el resto de las zonas, no tuvo una gran expansión de 1900 a 1950 , sino sólo un ligero incremento. A partir de esa fecha, el retroceso fue tal que hoy en dia presenta niveles de población muy inferiores a los registrados a principios de siglo.

3 En alguna de estas zonas, en concreto Riaño, encontramos factores añadidos desencadenantes del proceso de despoblación como han sido las consecuencias derivadas de la construcción del embalse del Esla, que afectó de forma directa a nueve entidades y en otros seis términos anegó parte del terrazgo productivo (MORALEjo MATEOS, M. ${ }^{\text {a }}$ P., 1992).

4 La presión humana sobre estos espacios de montaña era relativamente elevada para las posibilidades que ofrecian: el medio físico impone serias dificultades para el ejercicio de una agricultura rentable y, por ende, no se beneficiaron de procesos de diversificación de las actividades productivas. 
La manifestación más acusada del proceso es la débil densidad ${ }^{5}$ asociada a agudos procesos de despoblación, frágil presión demográfica sobre el territorio y pronunciado envejecimiento de los efectivos humanos (López FernÁndez, B., 1983). Hasta mediados de los años 60 la población a nivel provincial se distribuía de forma más o menos homogénea sobre el territorio, si bien ya se podía apreciar que las zonas de la orla montañosa ofrecían valores de ocupación inferiores. Hay que tener en cuenta que el umbral crítico por debajo del cual se estima que la vida no mantiene una actividad permanente se sitúa en los $10 \mathrm{~h} / \mathrm{km}$ cuadrado para las zonas de alta montaña, y en las C.A.E. leonesas muchos municipios sobrepasan por defecto dicho valor.

Las reducidas dimensiones de la mayoría de las entidades ${ }^{6}$ y municipios (tabla 3), unido a la dispersión espacial y a su emplazamiento marginal por sus caracteres físicos, hace que los gastos en infraestructuras y equipamientos por habitante sean muy elevados.

\section{TABLA 3. LOCALIDADES CON MENOS DE 10 HABITANTES EN LAS} C.A.E. DE LEÓN 1992

\begin{tabular}{lllc}
\hline C.A.E & MUNICIPIO & ENTIDAD & No HABITANTES \\
\hline CABRERA & Benuza & Santalavilla & 6 \\
BIERzO & Balboa & Fuente de Oliva & - \\
& & Ruideferros & 5 \\
& & Ruidelamas & 1 \\
& Pajarís & 9 \\
& & Barrosas & 6 \\
& Cruces & 9 \\
& Quintela & 9 \\
& Peñacaira & 7 \\
& Candín & Suárbol & 2 \\
& Villarbón & 4 \\
& Cencia & Leiroso & 7 \\
& Corullón & Peón & 3 \\
& Trabadelo & Paradela & 5
\end{tabular}

5 Supone un cuarto del total provincial y oscila alrededor de los 10 habitantes por kilómetro cuadrado. De forma particular, La Cabrera tendría 6,8 habitantes por $\mathrm{km}^{2}$; Riaño, 5,7 h/km²; Omaña, $8,9 \mathrm{~h} / \mathrm{km}^{2}$; Margatería-Cepeda, $8,4 \mathrm{~h} / \mathrm{km}^{2}$, y El Bierzo Oeste, 15,2 h// $\mathrm{km}^{2}$.

6 Más de la mitad de los núcleos de población tienen menos de 50 habitantes (de hecho) y el resto no sobrepasan los 100 . 
TABLA 3. LOCALIDADES CON MENOS DE 10 HABITANTES EN LAS C.A.E. DE LEÓN 1992

(continuación)

\begin{tabular}{lllc}
\hline C.A.E & MUNICIPIO & ENTIDAD & № HABITANTES \\
\hline MARAG-CEP. & Molinaseca & Castrillo & 1 \\
& & Folgoso & - \\
& Villamejil & Revilla & 9 \\
& Lucillo & Busnadiego & 10 \\
& & Piedras Albas & 5 \\
& Sta. Colomba & Argañoso & 5 \\
& & Prada de la S. & 6 \\
& & Rabanal Viejo & 10 \\
OMAÑA & Riello & Foncebadón & 2 \\
& & Manzaneda & 7 \\
RIAÑo & Robledo & 9 \\
& Cistierna & Valbueno & 9 \\
\hline
\end{tabular}

Fuente: Excma. Diputación Provincial de León. Elaboración propia

\subsection{Efectos de los movimientos naturales de la población}

La pérdida del tono vital en estos enclaves ha llegado a tal extremo que podríamos calificarlos como "comunidades de jubilados". La evolución experimentada por la dinámica natural de la población se relaciona de forma directa con los movimientos espaciales de los efectivos en edad reproductora.

Tradicionalmente, en las sociedades rurales no ha existido un fuerte control sobre los nacimientos. La nupcialidad era el regulador de la reproducción; sin embargo, el control natural vía matrimonio ha dejado paso a los métodos individuales de contracepción. Con ello, esta variable ha cedido importancia en su función demográfica.

La nupcialidad se sitúa en torno al 3,5\%, cifra sensiblemente inferior a la ya baja media provincial. Las causas de este desmedrado índice entran dentro del contexto demográfico recesivo del momento; no obstante, hemos de tener en cuenta las circunstancias especiales que aquí concurren. La emigración masiva y selectiva de la población joven ha incidido en el retroceso de los matrimonios con el consiguiente impacto en la natalidad; además, se ha producido una ruptura de los modos de vida tradicionales, y la crisis económica está influyendo sobre manera en estos espacios de 
equilibrio económico más frágil; todos estos factores conjuntamente aplazan los matrimonios hasta asegurar un puesto de trabajo menos sacrificado y mejor pagado que la agricultura de autoconsumo y, por consiguiente, fuera del entorno rural, con lo que entramos de nuevo en la dinámica emigratoria (GonZÁlez GonZÁlez, M. et al., 1986).

El panorama se presenta poco esperanzador para la recuperación de las áreas deprimidas, y el análisis del crecimiento natural lo agrava. Los efectos de una natalidad restringida y una mortalidad creciente se conjugan en un crecimiento vegetativo nulo e incluso inverso. La tasa de natalidad, secularmente superior a la mortalidad, ha trastrocado su ritmo instaurándose una tendencia recesiva y en continuo declive. La simbiosis entre dicha variable y una mortalidad al alza es, a la vez, causa y consecuencia del proceso de envejecimiento, que ha venido de la mano de la emigración (GARCíA ZARZA, E., 1983).

La recesión generalizada de los nacimientos ${ }^{7}$ durante el período intercensal 1981-1991 mantiene la tendencia heredada de períodos anteriores en los que la natalidad, siguiendo un trend casi paralelo al de la mortalidad, empezó a retroceder ${ }^{8}$, lo que indica un cambio en el comportamiento de los efectivos poblacionales ante la vida (tabla 4). Todos los municipios integrados en las C.A.E. tienen una natalidad inferior a la exigua cifra del 10 por mil, pero además no tienen capacidad de renovar sus generaciones ya que el número medio de hijos por mujer es inferior a 2,1 .

\section{TABLA 4. MOVIMIENTOS NATURALES DE LA POBLACIÓN Medias de 1981 a 1990 por mil habitantes}

\begin{tabular}{lccc}
\hline \multicolumn{1}{c}{ COMARCA } & NATALIDAD & MORTALIDAD & CREC. VEGETATIVO \\
\hline Bierzo & 7,8 & 10,1 & $-2,97$ \\
Cabrera & 8,8 & 11,2 & $-2,37$ \\
Maragatería-Cep. & 6,1 & 12,7 & $-6,63$ \\
Omaña & 8,2 & 11,9 & $-3,71$ \\
Riaño & 7,9 & 12,7 & $-4,88$ \\
Total provincia & 9,4 & 9,2 & 0,25 \\
Media nacional & 11,1 & 7,2 & 3,95 \\
\hline
\end{tabular}

Fuente: Excma. Diputación Provincial de León. Elaboración propia.

Por debajo tanto de la tasa provincial $(9,4$ por mil) como nacional $(11,1$ por mil).

8 La situación es más acusada en Maragatería-Cepeda, Bierzo y Riaño. 
En contra de lo que es normal en cualquier población "sana", la mortalidad es muy superior a la natalidad. El desfase entre ambas variables produce un incremento vegetativo que sobrepasa por debajo el punto de crecimiento cero, la tendencia a la involución demográfica constituye la nota dominante (PuYOL, R. 1982), situando a estas zonas en lo que algunos demógrafos denominan "quinta fase de la transición demográfica", caracterizada por regresión poblacional y por un alto índice de vejez (Pressat, R., 1981).

La mortalidad presenta una tendencia ascendente ${ }^{9}$, consecuencia de los relativamente altos indices de envejecimiento producido por la combinación de una fuerte emigración, tanto cuantitativa como cualitativa, con la reducción voluntaria de la natalidad, que afectó sobre todo a los municipios más pequeños. El crecimiento negativo se ha instaurado en la práctica totalidad de estos territorios por los que se extendió en forma de mancha de aceite desde los núcleos más aislados y marginales.

La concomitancia de la dinámica de los movimientos naturales de la población y el deterioro migratorio ha dado lugar a la culminación de un proceso evolutivo regresivo en el que la estructura demográfica no tiene capacidad para regenerarse de forma autosostenida.

Este hecho se ha visto contrarrestado puntualmente ${ }^{10}$ en alguno de los municipios a partir de la década de los ochenta, donde a pesar de registrarse un crecimiento vegetativo nulo, han experimentado pequeños aumentos de población.

A pesar de haberse contenido la salida de efectivos, esto no da lugar al alumbramiento de una salida a la atonía, pues la dinámica vital de los efectivos retornados no va a suponer cambios significativos para las variables nupcialidad y natalidad, pero si para el índice de mortalidad, puesto que, salvo algunas excepciones, son personas mayores de 65 años (Garcia Zarza, E., 1980).

La rémora que supone el comportamiento de la natalidad y la mortalidad, desde mitad de siglo, pone de manifiesto la falta de vitalidad de un régimen demográfico viejo, del que hay que partir como base para las exiguas posibilidades de restablecimiento (BIELZA DE ORY, V., 1984).

\footnotetext{
9 Los valores fluctúan entre el 10 y el 13 por mil.

10 Se constatan movimientos de retorno de emigrados en Molinaseca, Santiago Millas, Val de San Lorenzo (Maragateria).
} 


\subsection{Estructura de la población por edad}

El envejecimiento al que hemos aludido ha trastrocado las estructuras por edad, de tal manera que las pirámides han pasado de tener forma de parasol ${ }^{11}$ a ser claramente bulbiformes con lados convexos ${ }^{12}$. Empezando desde la base hacia el "remate", se aprecia una exigua longitud de las barras iniciales y medias fruto de la disminución de la natalidad y las emigraciones, mientras que las barras superiores adquieren mayor longitud reflejo del proceso de envejecimiento (fig. 2.). Esto denota por un lado un fuerte retroceso del grupo de jóvenes (de 0 a 14) y por otro una pérdida de población adulta joven (entre 15 y 34 años); la situación tiende a agravarse si tenemos en cuenta el alto peso relativo que ha adquirido en los últimos veinte años el grupo de mayores de 70 años.

La interrelación de los fenómenos demográficos ${ }^{13}$ queda así de manifiesto en la imagen evolutiva de las cohortes que muestran una población marcada por el envejecimiento (GonZÁLEZ MUÑOZ, C., 1983).

Una población se considera «equilibrada» si los tres grandes grupos de edad alcanzan los siguientes valores: jóvenes ( 0 a 14 años) $25 \%$ del total de la población; adultos (15 a 64 años) $65 \%$ de los efectivos y viejos (más de 65 años) 10\% del total poblacional (Veyret-Verner, G., 1959).

Comparando los porcentajes de las distintas categorías de edad registrados en nuestro ámbito de estudio, se puede apreciar el fuerte descenso sufrido por la población joven de todos y cada uno de los municipios, no llegando alguno de ellos ni al $10 \%{ }^{14}$.

La población adulta alcanza unos porcentajes inferiores al valor medio de su grupo, pero donde aparece una anomalía mayor es en la categoria de los mayores de 65 años (tabla 5), que representan más de dos cuartas partes de los efectivos totales ${ }^{15}$.

"Base ancha con disminución rápida hacia la cumbre. Representa una población joven con natalidad y mortalidad elevada (GonzÁLEZ MuÑoz, C., 1983).

12 Se trata de una población en declive, en proceso de envejecimiento (González MuÑoz, C., 1983).

13 Exodo masivo y crecimiento natural negativo.

14 Balboa, Candín, Oencia y Peranzanes en el Bierzo; Magaz en Maragateria-Cepeda; Riello en Omaña; Oseja y Burón en Riaño y Truchas en Cabrera.

15 Un colectivo humano con más de un $10 \%$ de ancianos se considera envejecido y con un grave “hándicap» para adaptarse a la dinámica de desarrollo (GoNZÁLEZ GonZÁLEZ, M. a J., 1991). 


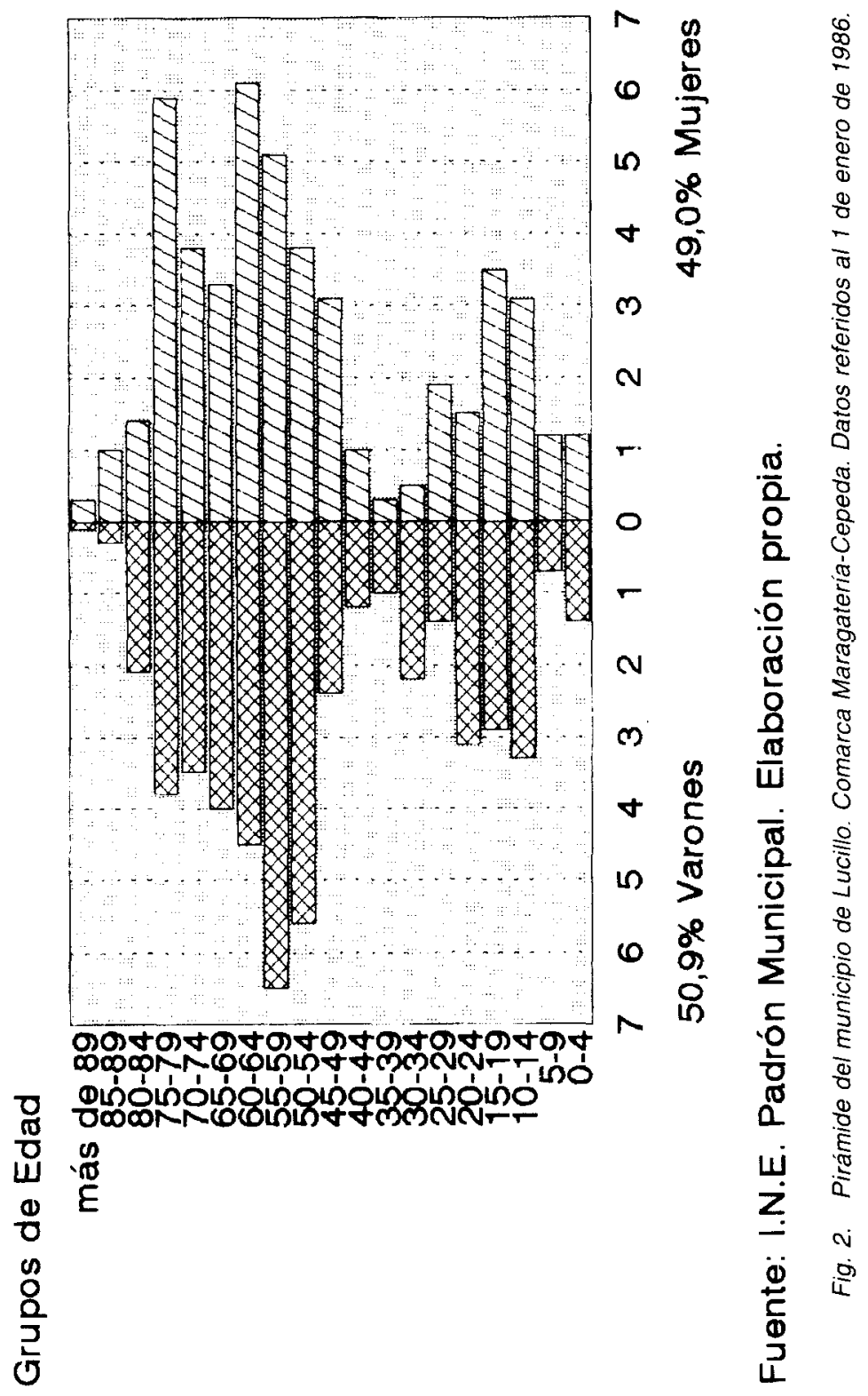


De lo anterior se deriva que el índice de dependencia demográfica es elevado ${ }^{16}$ y tendente al alza en contra de un recesivo índice de juventud, lo que condiciona de manera ostensible la dinámica socio-económica.

TABLA 5. GRUPOS DE EDAD POR COMARCAS

(Datos en \% referidos al 1 de enero de 1991)

\begin{tabular}{lccc}
\hline \multicolumn{1}{c}{ COMARCA } & JÓVENES & ADULTOS & VIEJOS \\
\hline Bierzo & 12,9 & 61,3 & 25,1 \\
Cabrera & 14,3 & 62,2 & 23,4 \\
Maragat-Cep. & 13,2 & 61,8 & 24,9 \\
Omaña & 16,9 & 61,7 & 21,2 \\
Riaño & 14,8 & 62,0 & 23,2 \\
\hline
\end{tabular}

Fuente: Rectificación del Padrón Municipal. Elaboración propia.

Ésta parece ser la situación de todos los municipios englobados en las Comarcas de Acción Especial, que se agrava en muchos casos a medida que aumenta el número de ancianos ante la prolongación de la esperanza de vida (SAGRedo García, J., 1980), si bien una población se considera envejecida no sólo cuando cuantitativamente el número de personas mayores de 65 años es elevado, sino cuando su peso relativo sobre la población total alcanza valores discordantes.

\subsection{Estructura de la población por ocupación}

Una de las características principales de la población de las zonas deprimidas es su acentuado carácter rural. Con ello no sólo hacemos referencia al hecho de que residen en hábitats rurales sino sobre todo a que desempeñan actividades agrarias.

La emigración hacia las zonas del país donde se concentró el proceso industrial dio lugar a una reordenación social y económica de estos espacios: la población sufrió un profundo cambio que exigió la reestructuración sectorial de los activos ${ }^{17}$.

La distribución de la población entre las categorías activa y pasiva no puede ser más reveladora (tabla 6 ), pues en general los activos no sobrepasan el $40 \%$, mientras que las clases pasivas están muy por encima del $50 \%$.

16 Sensiblemente superior al nacional.

17 Uno de los indicadores más sensibles de la actividad económica de una comarca, región o pais es el comportamiento de la población activa (GONZALEZ GONZALEZ, M. ${ }^{\text {J., }}$ 1991). 
Crisis y posibilidades de activación socioeconómica de las zonas deprimidas...

TABLA 6. POBLACIÓN ACTIVA Y PASIVA (1986)

\begin{tabular}{lcrrc}
\hline \multicolumn{1}{c}{ COMARCA } & P. ACTIVA (\%) & P. OCUP. & P. PARAD & P. PASIVA (\%) \\
\hline Bierzo Oeste & 29,53 & 87,69 & 12,31 & 70,47 \\
Cabrera & 30,70 & 95,05 & 4,95 & 69,30 \\
Maragatería-Cep. & 36,59 & 84,28 & 15,72 & 63,41 \\
Omaña & 31,22 & 82,22 & 11,78 & 68,78 \\
Riaño & 30,70 & 94,72 & 5,28 & 69,30 \\
\hline
\end{tabular}

Fuente: Excma. Diputación Provincial de León. Elaboración propia.

El proceso de cambio tuvo carácter global y aparentemente irreversible. En primer lugar se produjo una rápida reducción de los activos agrarios; el sector primario perdió más del cuarenta por ciento de sus puestos de trabajo a lo largo de las tres últimas décadas. Entre los factores desencadenantes de la inflexión sufrida por la hasta entonces ascendente población agraria destacan el paso de una agricultura de autoconsumo a una comercial y la salida de los jóvenes en busca de empleo urbano. No obstante, las actividades que más empleo generan son las primarias, que sobrepasan el $50 \%$ de los activos ${ }^{18}$; le sigue el sector secundario ${ }^{19} \mathrm{y}$, en último término, el terciario ${ }^{20}$, aunque con notables diferencias interterritoriales. Son sociedades eminentemente rurales agroganaderas, donde no se ha llevado a cabo plenamente la intensa transformación productiva sufrida en otras comarcas cercanas, con un sector servicios poco desarrollado y puntual que no se puede considerar como un sector laboral dinámico y una industria de tipo familiar ligada a la explotación de los recursos autóctonos con una capacidad de absorción de mano de obra muy limitada (CABERo DIÉGUeZ, V., 1980).

\section{EVALUACIÓN DE LA SITUACIÓN ECONÓMICA}

Estas viejas comarcas agrarias, con estructuras productivas arcaicas, han entrado en una crisis involutiva provocada por el ajuste productivo que fue necesario realizar a partir de los años sesenta y se ha acentuado

ro En algunos municipios sobrepasan el $80 \%$ (Balboa, Lucillo, Luyego, Santa Colomba, Castrillo, Truchas, Riello, Acebedo y Burón).

19 Representado por las actividades minero-extractivas de la Cabrera y las del municipio de Igüeña en Omaña; las hidroeléctricas y toda una serie de pequeñas empresas pseudo-artesanales diseminadas por todas y cada una de las comarcas a las que nos referimos.

20 En Riaño y Valdeón se están desarrollando una serie de actividades orientadas al turismo (hosteleras, comerciales...). 
de manera especial la tradicional debilidad de su sistema económico durante la última década. En estas regiones desfavorecidas, el desajuste entre la producción y la demanda es más evidente: no existe un crecimiento del empleo alternativo, no se cuenta con recursos humanos suficientes para que despegue el desarrollo...; en definitiva, se ha producido un gran cambio en la economía tradicional y, sobre todo, en su elemental sistema productivo, de manera que si pretendiésemos analizar la realidad de estos singulares modelos económicos de tipo familiar no sería significativo el uso de indicadores cuantitativos como la renta "per cápita", el poder adquisitivo, nivel de consumo, etc.

\subsection{El sector primario: Agricultura, ganadería y silvicultura}

La actividad agraria ejercida sobre pequeñas explotaciones cubre la mayor parte de las necesidades familiares. La estructura de la propiedad se caracteriza por unidades multifragmentadas (tabla 7), dispersas por el terrazgo, de dimensiones muy reducidas ${ }^{21}$ lo que ha favorecido la pervivencia de modos de producción arcaicos (Astorga González, A. F., 1993). La superficie agraria útil (S.A.U.) oscila entre el 1 y el $5 \%{ }^{22}$ debido a la reducción experimentada en los últimos años por el abandono de tierras por parte de los emigrados y la jubilación de los empresarios que no se han visto relevados al frente de la explotación por las exiguas generaciones jóvenes. El abandono del espacio productivo se aprecia tanto en los secanos como en los comunales y el monte, estos últimos de gran importancia en otros tiempos cuando la presión poblacional obligaba a roturar el máximo de tierras y buscar recursos complementarios a una agricultura de subsistencia ejercida sobre terrenos de escasa calidad (LuENGo UGidos, M.A., 1984). Siguiendo criterios puramente economicistas, la rentabilidad de las explotaciones, mayoritariamente menores de 5 hectáreas, es mínima, ya que las producciones son bajas y muy diversificadas, es decir, incluyen parte de labradío donde se cultivan cereales y plantas forrajeras; huertos con frutales, legumbres y verduras; pastos y un número variable de cabezas de ganado, todo en función de las necesidades de autoconsumo familiar. Sin embargo, la extensión dedicada a prados, praderas y pastizales es mayoritaria dentro de cada unidad de

\footnotetext{
21 El minifundismo es una de las caracteristicas endémicas en las explotaciones, cuyas dimensiones medias por parcela no llegan a media hectárea (GONZÁLEZ VECIN, J., 1979).

22 Solamente en Maragateria-Cepeda la tierra labrada alcanza el $12 \%$ del total de la superficie.
} 
explotación, lo que indica, al menos sin analizar más variables, una mayor dedicación ganadera. De todos modos, no existe una producción intensiva ni orientación pecuaria definida, el sistema suele ser de carácter mixto ${ }^{23}$ y con un reducido número de cabezas. Por otro lado, el aprovechamiento de los pastos, praderas y pastizales no es racional, en función de la carga ganadera que pueden soportar, bastante superior al número real de reses que sustentan. Esto da lugar a la expansión del matorral por estos terrenos escasamente aprovechados para la actividad pastoril, incrementándose así los riesgos de incendio y los procesos de desertización.

\begin{tabular}{|c|c|c|c|c|c|}
\hline COMARCA & TOT. EXPLOT. & -5 HAS. & $5 \mathrm{~A} 10 \mathrm{H}$. & $10 \mathrm{~A} 20 \mathrm{H}$. & $+20 \mathrm{H}$ \\
\hline Bierzo & 5.251 & 94 & 5 & 1 & - \\
\hline Cabrera & 1.613 & 89 & 5 & 1 & 5 \\
\hline Marag-Cep. & 3.721 & 56 & 21 & 16 & 7 \\
\hline Omaña & 1.214 & 75 & 18 & 4 & 3 \\
\hline Riaño & 1.262 & 39 & 2 & 2 & 14 \\
\hline
\end{tabular}

Fuente: Excma. Diputación Provincial de León. Elaboración propia.

El alto grado de parcelación es una de las características más negativas de las explotaciones agrarias, fruto del sistema tradicional de herencias, que aún no ha sido subsanada. La solución vendría de la mano de la roncentración parcelaria, cuyo fin es reducir el número de parcelas a la vez que se reunifican todas las de un mismo propietario, y así podria rentabilizarse el uso de la maquinaria ${ }^{24}$, el aprovechamiento del agua en los regadíos y reducir el tiempo dedicado a desplazamientos dentro de una misma explotación (FERRERAs Chasco, C., 1981). Sin embargo, la oposición popular a la puesta en práctica de estas medidas por la resistencia que existe a los cambios en zonas de costumbres tan enraizadas y la falta

\footnotetext{
23 Se destinan tanto a la producción de carne como a la de leche e incluso a la tracción de arados y carros.

24 El nivel de mecanización es bajo y, además, la maquinaria disponible se infrautiliza. Por razones orográficas (la pendiente supera en algunas áreas el $30 \%$ ) y por la estructura minifundista de la propiedad, la mayor parte de la superficie agraria se trabaja con motocultores o utilizando tracción animal. En las reducidas parcelas, sobre todo de los regadios, es muy dificil la maniobrabilidad y el acceso de las grandes herramientas, por lo que los escasos tractores son utilizados casi exciusivamente en labores de transporte y acarreo.
} 
de información adecuada que venza las desconfianzas y el rechazo, dificultan la resolución del problema ${ }^{25}$.

La ganadería ha estado ligada a objetivos productivos de autoabastecimiento, ya que sólo los excedentes eran comercializados. De aquí se deriva la configuración de las actuales explotaciones de carácter familiar y minifundista, supeditadas a la agricultura, en las que no se siguen criterios de competitividad mercantil, lo cual eleva los costes productivos y disminuye los márgenes de ganancia en las ventas, oscureciendo así el futuro de este subsector (FERNÁNDEZ, F., 1983). Este sistema de explotación entró en crisis desde el mismo momento en que dejó de estar orientado al autoconsumo y pretendió integrarse en el contexto económico actual en el que uno de los objetivos prioritarios de la P.A.C. es la reducción de los productos excedentarios como la leche y donde imperan criterios de competitividad. Se aprecian así de forma más acuciante los problemas fundamentales que cuestionan la continuación de las actividades pecuarias, sobre todo de vacuno, como son las insuficientes dimensiones de las explotaciones ${ }^{26}$, los bajos rendimientos por animal, el reducido volumen de producción por explotación y los derivados de las deficientes comunicaciones que tradicionalmente han sido un freno para el aprovechamiento de los recursos naturales ${ }^{27}$.

Las especies ganaderas tradicionales han sido, por orden de importancia, el vacuno (explotado en régimen mixto, fuerza de trabajo auxiliar en las tareas agrarias y fuente de alimento humano), lanar, caprino, caballar y mular, sin menospreciar el porcino y las aves de corral. Actualmente, atendiendo solamente a datos estadísticos, podemos confirmar que el ganado ovino es el que cuenta con un mayor censo en el conjunto zonal que estudiamos ${ }^{28}$. La existencia de grandes superficies comu-

25 La concentración parcelaria no puede considerarse como la panacea para reorganizar de forma más racional la estructura de la propiedad, sobre todo si tenemos en cuenta el carácter accidentado de la topografía en estas zonas.

26 A esto hay que añadir que las instalaciones de estabulación son muy deficientes; la inversión en edificaciones ganaderas es casi nula, utilizándose "cuadras" antiguas, anexas o englobadas en las viviendas, que no reúnen ni siquiera las mínimas condiciones higiénicas.

27 La dispersión geográfica y el estado de las infraestructuras de transporte elevan los costes de recogida de la producción y el mantenimiento de una cabaña saneada, obstaculizando la difusión de innovaciones. Por otro lado, apenas hay movimientos de tipo cooperativista o asociacionista que agrupe a los productores para obtener mayor rentabilidad.

${ }_{28}$ La orientación hacia las especies ovina y caprina es predominante en Maragateria-Cepeda y Cabrera, donde hay censados rebaños de tamaño considerable; sin embargo, las explotaciones de bovino son, aunque más numerosas, de reducidas dimensiones (no sobrepasan la media de 10 cabezas) en régimen extensivo. La cabaña de vacuno es, por el contrario, más importante en el resto de las C.A.E., ya que los pastos tienen mayor calidad. 
nales e improductivas permite en la actualidad una producción a bajo coste. Por otro lado, las ayudas comunitarias han estimulado un cierto incremento del número de cabezas, una reestructuración de las explotaciones y, por consiguiente, una mejora de la situación económica de los ganaderos. No obstante, la producción orientada al mercado exige la modernización de las estructuras, la introducción de innovaciones, la adaptación a las reglas del mercado y una serie de cambios que hoy por hoy no se pueden acometeter en estas zonas.

La falta de rentabilidad económica de las explotaciones familiares ha hecho que los ingresos deban ser complementados con otras actividades productivas como la silvicultura, la artesanía, apicultura, chacinería,...

Los montes, pieza básica en la organización económica tradicional de estos espacios de montaña, han servido para la obtención de leñas, madera y pasto complementario, lo que provocó una importante deforestación; hoy, a pesar de que las condiciones orográficas y edafológicas son favorables para el desarrollo de este subsector, la silvicultura sólo tiene relevancia en el término de Tabuyo del Monte (C.A.E. de Maragateria-Cepeda), donde se extrae resina de los comunales repoblados de pinos. A pesar de que las actividades extractivas sobre los montes están más controladas o, al menos, son ejercidas por una población mucho menos numerosa, la masa forestal se sigue reduciendo por la proliferación de incendios ${ }^{29}$, fortuitos o provocados, que contribuyen a destruir uno de los recursos más importantes para el desarrollo armónico de estas zonas. El fomento del sector forestal puede absorber parte de la mano de obra excedentaria en la agricultura y ganadería y asi ser un revulsivo para la fijación e incluso atracción de población hacia estas áreas en proceso de abandono. Indirectamente puede contribuir a crear empleo por el fomento del turismo rural y la creación de industrias transformadoras de la madera próximas a la fuente de materia prima.

A todas estas limitaciones del sector primario hay que añadirle el elevado envejecimiento de los empresarios. Sólo el 2 ó $3 \%$ de los agricultores tienen menos de 35 años; un 31-32\% tienen entre 35 y 54 años y del 28 al $32 \%$ cuentan con una edad que oscila entre 54 y 65 años. Las connotaciones socioeconómicas de este fuerte envejecimiento son, entre otras, la perpetuación de las explotaciones tradicionales (lo que da medida de las dificultades que existen en estas zonas para introducir cambios en las

29 Las consecuencias de estos hechos son muy graves, ya que conducen a fuertes y a veces irreversibles erosiones del terreno y a un deterioro general del frágil medio. 
estructuras productivas), los cultivos, aperos, etc; puesto que el principal objetivo de los empresarios maduros es obtener rentabilidad económica a corto plazo, saben que la explotación de los minifundios siempre les garantiza la subsistencia ${ }^{30}$.

\subsection{Industria y servicios}

En un análisis retrospectivo, podemos apreciar que históricamente se han desarrollado en estas zonas marginales actividades de tipo artesanal, complemento indispensable a la economía agraria de subsistencia ${ }^{31}$; sin embargo, no ha existido una actividad fabril destacada.

La herencia de estas actividades se reduce a mero testimonio, pues si excluimos el despegue puntual que tuvo la fabricación de mantas de lana en maragatería, hoy apenas algunos jubilados obtienen modestas rentas adicionales transformando la madera en rústicos utensilios de cocina y en madreñas para uso de sus vecinos.

Estas comarcas, debido a su posición marginal frente a otros espacios provinciales, vieron convulsionado su modelo tradicional de organización económica, ya que por sí mismas no fueron capaces en su momento de promover actividades generadoras de empleo que fijasen la población y, actualmente, la dotación humana no cuenta con vitalidad ni dinamismo que justifiquen la decisión empresarial de instalar en ellas industrias (MANERO, F., 1983).

Dentro de la atonia demográfica y económica señalada existen algunos islotes más dinámicos, considerados como cabeceras de comarca, cuya función es articular las relaciones entre el territorio que las circunda y el exterior. Nos referimos a enclaves como Puente de Domingo Flórez y la Baña en La Cabrera; Vega de Espinareda y Villafranca en Bierzo Oeste; Val de San Lorenzo y Magaz en Maragatería-Cepeda; Riaño y Posada de Valdeón en Riaño; y Riello en Omaña. En la mayor parte de ellos la actividad industrial hace tímidamente acto de presencia a través de pequeñas factorias aisladas, directamente relacionadas con el sector primario, pero

30 La agricultura se orienta únicamente al sustento familiar, las explotaciones no se rigen por criterios productivistas. Los agricultores son reacios a la aplicación de innovaciones debido al peso de arraigadas costumbres, a la formación recibida y at limitado tiempo laboral que se abre ante si (Pressat, R., 1981).

31 Fabricación artesanal de aperos de labranza, fibras para la confección de vestidos, harinas y aceite, la arriería.... 
Crisis y posibilidades de activación socioeconómica de las zonas deprimidas...

son las actividades comerciales y de servicios en general las que les confieren su operatividad funcional ${ }^{32}$.

Uno de los fines últimos de los Planes de Desarrollo diseñados para estas zonas desfavorecidas inciden en la implantación de un tejido empresarial proporcional al nivel de producción de materias primas ${ }^{33}$ que garantice un crecimiento del empleo. Hoy por hoy, el sector industrial es aún muy limitado en cuanto a la ocupación de mano de obra y diversidad de actividades en tanto que la mayoría de las industrias son de tipo familiar o al menos no sobrepasan los 20 empleados.

La superación de este estado de declive y, por tanto, la inserción de estas zonas en la dinámica industrial es difícil a corto plazo ya que la naturaleza a pesar de ofrecer algunas materias primas interesantes para iniciar la actividad transformadora (castañas en el Bierzo, Pizarras en La Cabrera, productos porcinos en Maragatería, plantas aromáticas,...), choca con el freno que supone el estado de precariedad de las infraestructuras, las limitaciones del mercado y la escasez y baja cualificación de la mano de obra (VV.AA., 1989).

Los profundos contrastes interprovinciales se hacen aún más acusados si tenemos en cuenta los importantes déficits y carencias de los más elementales servicios y equipamientos colectivos que existen en las comarcas deprimidas. Allí las necesidades tienen que cubrirse siempre previo un desplazamiento hasta los sobredotados núcleos de mayor entidad jerárquica ${ }^{34}$. Estos centros «terciarios» con atracción limitada a toda una comarca o incluso sólo a un valle, están fuera en muchos casos de la C.A.E.

Aunque las conexiones con el espacio circundante son fuertes y arraigadas en el tiempo, el acceso a los servicios está, no obstante, limitado por factores infraestructurales y de tipo físico. Así, las deficiencias en transportes colectivos ${ }^{35}$, las considerables distancias relativas entre los núcleos de población, maximizadas por los tortuosos trazados de las vías,

32 Canteras de pizarras paleozoicas en La Cabrera con 30 explotaciones que dan empleo a más de 500 personas, la chacinería en Maragateria-Cepeda, la hosteleria en Riaño, sobre todo en los municipios de los Picos de Europa, la minería y los transportes en el Bierzo Oeste, y los servicios destinados al ocio en el resto de las comarcas.

${ }^{33}$ Industrias de productos cárnicos, derivados lácteos, envasadora de plantas silvestres, de primera transformación de la madera, talleres textiles...

34 Donde el juego de la oferta y la demanda produce rentabilidad y donde la accesibilidad es tal que pone los servicios al alcance de la mayor parte de los potenciales usuarios.

35 Algunos municipios no disponen de lineas regulares de transporte colectivo de viajeros (Benuza en La Cabrera). 
y las inclemencias climáticas invernales que cortan las comunicaciones durante ciertos períodos de tiempo (Cortizo Álvarez, J., 1989).

El comercio rural sobrevive estancado tanto morfológica como estructuralmente ${ }^{36}$. Los establecimientos suelen ser mixtos, aglutinando una mezcla de varias licencias (taberna-tienda). La compra-venta de bienes de consumo se ejerce en locales de mínimas dimensiones, normalmente el portal ${ }^{37}$ o alguna de las habitaciones de la vivienda del comerciante, donde se ofrece "de todo" a elevados precios, aprovechando la situación de monopolio que tienen estas tiendas para un ámbito territorial más o menos extenso (López Trigal, L., 1979).

La desarticulada estructura de la población y el poblamiento junto con la debilidad de la demanda son la causa principal de la limitada oferta de bienes y servicios. Se justifica así, por razones económicas, la concentración geográfica de las actividades terciarias(educación, sanidad,...) en determinados puntos, que presumiblemente facilitan el acceso a ellos de todos los usuarios (Cortizo Álvarez, J., 1989).

Equipamientos básicos como el alumbrado público, el agua corriente, el alcantarillado, recogida de residuos sólidos o el asfaltado de calles y plazas son ventajas de las que la mayoría de las entidades no disfruta a pesar de los esfuerzos que en favor de su instalación se están haciendo desde las instancias administrativas provinciales.

El estado de las carreteras es precario y la irregularidad del trazado se une a un firme en mal estado ${ }^{38}$ y unas no menos duras condiciones meteorológicas que obstaculizan o impiden el tránsito rodado en determinadas épocas del año.

Esta relación de datos puede servir para dar idea de la discriminación y abandono que sufren estas áreas. Su aislamiento contribuye a incrementar los desequilibrios territoriales $y$, por otra parte, a reforzar la permanencia de los rasgos socio-económicos de subsistencia que las caracterizan, asi

36 Los establecimientos se mantienen apegados a las fórmulas tradicionales del comercio, practicando aún modos y sistemas de venta anclados en el pasado (mercancias a granel, horarios relajados, pagos a cuenta, oferta de empleo nula, trueque,...).

37 En las viviendas tradicionales leonesas aparece el «portal» como elemento vertebrador de las casas; especie de antesala distribuidora que a veces ejercia la función de cobijo para el carro y los aperos de labranza.

38 Especialmente deteriorado en zonas de La Cabrera donde el endeble firme es recorrido varias veces al dia por camiones de gran tonelaje que transportan las pizarras desde las canteras. Las inversiones en su restauración son nulas no tanto por problemas burocráticos de titularidad como por falta de partidas presupuestarias. 
como las relaciones de dependencia y subordinación que mantienen respecto a otros espacios más desarrollados.

\section{PROBLEMAS Y ALTERNATIVAS DE RESOLUCIÓN AL PROCESO DESARTICULADOR}

Las áreas periféricas de la provincia de León se han visto inmersas en una dinámica evolutiva que ha abocado en una profunda crisis socioeconómica de tal manera que es aquí donde se localizan las mayores «bolsas de pobreza".

Las partidas presupuestarias que anualmente los Órganos de Gobierno autonómicos y provinciales destinan a la recuperación económica y la conclusión de la situación marginal por la que atraviesan estas zonas mediante el desarrollo de los recursos autóctonos, apenas han logrado mitigar las duras condiciones de vida en algunos de estos núcleos.

Los atractivos ecológicos de estas comarcas montanas, verdadero patrimonio natural, son innumerables, tanto para los amantes de la práctica de deportes no convencionales y los naturalistas como para los que buscan simplemente un lugar de descanso. Pero no resulta fácil potenciar el turismo rural cuando el sistema viario de acceso son carreteras o pistas cuyo trazado, firme, pavimento y anchura no se adecuan al tráfico rodado que soportan. Por otro lado, su conservación resulta difícil y muy costosa, pues estacionalmente sufren graves deterioros (fisuras, socavones...) por causas climáticas.

Al mismo tiempo, no existen posibilidades reales de grandes cambios en cuanto al grado de bienestar y el nivel económico, pues la capacidad de respuesta de estos frágiles espacios es muy débil. Los condicionantes físicos y socio-coyunturales tienen un considerable peso negativo, a to que se añade la falta de generaciones jóvenes, emprendedoras y abiertas que luchen por trocar la situación de declive.

Los factores que contribuyen a acentuar el proceso de desarticulación son el aislamiento físico y cultural, la decadencia de las actividades tradicionales, la inexistencia de una industria transformadora de los productos autóctonos de cada C.A.E., que sea a la vez estímulo económico y fuente de empleo alternativo, la despoblación y el envejecimiento (consecuencia de los fuertes flujos emigratorios padecidos desde principios de siglo y el descenso de la natalidad), el abuso que desde la ciudad se ejerce sobre estos paisajes, la escasez de servicios, la inexistencia de infraestructuras básicas, el bajo nivel de renta y el evidente empobrecimiento en todos los órdenes. 
Sin duda quedan muchas trabas que superar antes de poner en marcha soluciones viables, pero ante todo deben aprovecharse las oportunidades que brinda la Administración para crear las bases infraestructurales y el sistema de equipamientos mínimo que atraiga flujos de desarrollo. Acciones que racionalicen la utilización del suelo y la explotación agropecuaria junto con la organización de actividades productivas secundarias y terciarias relacionadas con las potencialidades naturales, podrian estimular el asentamiento de algunos emigrados o, al menos, evitar la salida de los jóvenes.

Se propone, pues, un programa de desarrollo global para cuya materialización y éxito son necesarias como condición «sine qua non» algunas inversiones en reordenar el hábitat. No obstante, las Administraciones locales deben evitar que las ayudas se destinen exclusivamente a una remodelación morfológica de los cascos urbanos, pues sería una medida positiva sólo a corto plazo que llevaría a un "desarrollo fantasma". Se precisa ante todo una financiación adecuada que active el sector base de la economía para lograr un relanzamineto endógeno. Sería aconsejable que el desarrollo fuera fruto de la participación en todas las fases del proceso de los principales interesados, los lugareños, pues existen experiencias que demuestran que un plan de desarrollo hecho y gestionado por personas ajenas al espacio que se pretende reactivar, encuentra más dificultades y oposiciones que uno "hecho desde dentro".

Los objetivos operativos planteados serian más factibles de conseguir a través de una serie elemental de estrategias de actuación que podrian tener fácil aceptación, rápida difusión y resultados económico-sociales favorables como son: la potenciación de la ganadería atendiendo a la orientación de cada zona hacia una especie determinada y teniendo como metas la selección ${ }^{39}$, alimentación adecuada y sanidad; aprovechamiento racional de las masas arbóreas, combinando prácticas de extracción de productos forestales con las de repoblación con especies autóctonas. Es necesario lograr armonizar los usos productivos de los montes, fuente de ingresos complementarios y de puestos de trabajo, con los usos de conservación de estos importantes espacios naturales ${ }^{40}$;

39 Los pilares fundamentales de toda explotación ganadera que pretenda ser competitiva son: la mejora genética, la racionalización del aprovechamiento de los pastos y la reforma y mecanización de las instalaciones, vigilancia sanitaria, introducción de medidas higiénicas,...

40 La conservación de la estructura y dinámica del monte se puede conseguir a través del cuidado de las masas existentes, regulación de las talas, penalización de las quemas del monte bajo para obtener pastos, promoción de la recogida de especies como el tomillo, orégano, romero, arándanos..., muy extendidas en estas zonas y demandadas en el mercado, etc. 
explotación de las zonas agrarias de regadío (introducir cultivos forrajeros, mejorar y enriquecer los suelos, ordenar los cultivos e introducir especies nuevas, difundir las ventajas de la Concentración Parcelaria); promoción del turismo y la industria artesanal de transformación de productos locales ${ }^{41}$.

Otra serie de medidas tendentes a agilizar los cauces adecuados para el desarrollo serían: acometer las obras de dotación de infraestructuras y equipamiento en los núcleos urbanos (creación de espacios de recreo, asignación de utilidad a los edificios públicos abandonados, pavimentación y alumbrado de las calles,...), mejorar los servicios colectivos (mancomunar la recogida de residuos sólidos, aumentar las líneas de transporte, reparar y ampliar la red de saneamiento,...), promoción de la cultura autóctona, constitución de sociedades y cooperativas que faciliten los cauces tanto de la producción como de la venta de productos agrícolas, ganaderos, forestales y artesanales, y, por último, estimular la concentración de la población en las cabeceras municipales, dotándolas para ello de los servicios óptimos que satisfagan las demandas de los efectivos humanos.

A pesar de que hemos esbozado un pequeño programa de actuación para dinamizar las actividades económicas y, en general, la vida en estas zonas leonesas deprimidas, dada la realidad de la estructura de la propiedad, explotaciones, producción, equipamientos y la grave desarticulación demográfica, por nuestra parte vemos que no es probable un desarrollo a corto plazo de no acometerse medidas que sienten unas bases económicas sólidas. No es aconsejable un "desarrollo fantasma", basado en la obtención de subvenciones para mantener un determinado nivel de vida alcanzado mediante la implantación de actividades discordantes con el medio, los recursos naturales y la tradición socioeconómica de cada zona. Las propuestas aportadas podrían equipararse a un modesto programa global de ordenación rural que se desarrollaría en base a los recursos autóctonos y todos aquellos otros que la Administración pueda facilitar para evitar la total e irreversible degradación de estas áreas.

\footnotetext{
41 El turismo rural y el agroturismo son nuevas formas de canalizar el tiempo de ocio, que se están introduciendo rápidamente desde Europa, y cuyo fin es dar satisfacción a la demanda en este sentido de la población urbana. Se presenta como una alternativa al turismo tradicional y puede ser un elemento clave para el desarrollo que no sólo genere beneficios directos, sino que también contribuya al desarrollo y creación de pequeñas industrias (artesanales, de servicios,...) de cuya actividad se deriven rentas adicionales.
} 


\section{CONCLUSIONES}

La pervivencia de un sistema productivo tradicional en zonas con adversas condiciones naturales, suelos de baja productividad, potencial demográfico insuficiente y problemas de comunicación internas y exteriores ha llevado a la progresiva dominación de estos espacios geográficos por otros más dinámicos. Las economías rurales de montaña, orientadas aún hoy hacia la subsistencia, han sido el origen de gran parte de la mano de obra urbana e industrial. Durante decenios la carga demográfica fue muy superior a la que el pobre terrazgo microparcelado por sucesivas herencias y trabajado con aperos, formas y sistemas de cultivo arcaicos podia mantener. Se comprende fácilmente que las comarcas desfavorecidas de la provincia de León hayan sido desde comienzos de siglo focos emisores de población hacia todos los puntos cardinales de nuestra geografía, hacia Europa y ultramar. Este hecho vino, en contra de lo que se pudiera esperar, a agravar la situación, en tanto que la sangría migratoria acentuada desde mediados de esta centuria ha reducido al mínimo el potencial demográfico, limitando el tono vital y la capacidad de desarrollo económico endógeno autosostenido. La sangría de población joven ha sido tan acusada que la estructura demográfica se halla totalmente desarticulada, con un elevado porcentaje de adultos-viejos y, consecuentemente, una dinámica biológica regresiva.

Todo ello ha ocasionado un estancamiento económico, social y cultural; las actividades primarias están en crisis y el resto de los sectores se hallan tímidamente representados, por lo que no se pueden considerar como posibilidades alternativas para la reactivación. Las comunidades rurales marginales se han visto inmersas dentro de un proceso involutivo en el que como resultado un considerable número de núcleos puede quedar abandonado.

Junto al proceso de abandono de este ámbito se están produciendo nuevas formas de explotación acordes con los intereses militares (Campo de Tiro del Teleno), civiles (canteras a cielo abierto) y de los propietarios de la tierra residentes en las ciudades(construcción de segundas residencias morfoestructuralmente alejadas de la arquitectura tradicional autóctona, plantación de choperas en los mejores terrenos de vega,...), que se oponen en gran medida a su ordenación y planificación.

Desde muchas instancias se considera que las políticas de infraestructuras locales son la única solución para reactivar, a través de la mejora de la calidad de vida, estos espacios desfavorecidos. Sin embargo este tipo 
de medidas correctoras sólo sirven para corregir de forma cuantitativa los profundos desequilibrios territoriales que existen, ya que las nuevas infraestructuras a su vez pueden actuar, y de hecho lo hacen, como factores negativos adicionales en tanto que estos recursos se asignan a zonas donde su productividad va a ser escasa o nula, acrecentándose así las deficiencias cualitativas ${ }^{42}$.

Son necesarios programas de desarrollo global equilibrado que potencien las pocas bazas económico-sociales más fuertes que existan en cada comarca para que estas, a su vez, pongan en marcha mecanismos que superen el estado de atonia. Las políticas territoriales deben desempeñar un papel capital en la organización de estos territorios, sobre todo en lo que se refiere a la priorización y racionalización de las inversiones y ayudas, de acuerdo siempre con las iniciativas locales.

\section{RESUMEN}

Las características del medio físico en las C.A.E. de la provincia de León condicionan el desarrollo del sector base de la economía, las actividades agrícolas y ganaderas. Por otro lado, las técnicas empleadas y las estructuras son anacrónicas e impiden la capitalización, exigiéndose por ello una inmediata modernización.

La emigración ha sido tan acusada desde comienzos de siglo que la estructura demográfica se halla totalmente desarticulada, con un elevado porcentaje de ancianos.

Todo ello, acompañado de la falta de un sector de actividad económica alternativo y unas infraestructuras y equipamientos deficientes, ha provocado un estancamiento económico, social y cultural.

La recuperación de estas zonas necesita fuertes mejoras para retener a la población joven que aún queda, encaminadas tanto a la dotación de equipamientos como a la inversión en creación de empresas y alternativas de empleo.

Palabras clave: Desarticulación económica, éxodo masivo, envejecimiento, plan global, dinamización.

42 En La Cabrera, el alumbrado público instalado por la Excma. Diputación Provincial se haya fuera de uso porque las viviendas en las que se fijaron los puntos de luz se han derrumbado y no existen recursos suficientes para la reparación y mantenimiento de esta dotación. 


\section{RÉSUMÉ}

Les caractéristiques du milieu physique dans les C.A.E. de la province de León conditionnent le développement du secteur économique de base, les activités agricoles et du bétail. En plus, les techniques utilisées et les structures sont anachroniques, et ne permettent pas la capitalisation, ce qui exige une modernisation inmédiate.

L'émigration a été si importante à partir du comencement du siécle que la structure demographique se trouve totalment desarticulée, avec un pourcentage très élevé de personnes agées.

Toute cette situation, acompagnée de l'inexistence d'un secteur d'activité économique alternatif et de la pauvre qualité de ses infraestructures et de ses équipements, a provoqué une stagnation économique, sociale et culturelle.

La récupération de ses zones doit subir de grands améliorations pour pouvoir retenir la population jeune qui y demeure encore. Améliorations qui doivent être dirigées tant à la dotation d'équipementes comme à l'inversion pour la création d'entreprises et autres alternatives d'emploi.

Mots Clé: Désarticulation économique, Exode massif, Vieillissement, Projet total, Développement.

\section{SUMMARY}

The characteristics of the geographic conditions in the Specially Financed Regions in the Province of León condition the base sector of the economy and forming activities. However, the techniques used and the structures are anachronistic and prevent capitalization, which demands immediate modernization.

Emigration has been so prononced since the beginning of this century that the demographic structure is totally dislocated, having a high percentage of elderly people.

This, together with the lack of a sector of alternative economic activity and infraestructures and defective equipment, has provoked an economic, social and cultural standstill.

The recovery of these areas needs strong improvements in order to retain the young people who still remain, guidance both in establisting of equipment and in investment in order to set up companies and alternative employment.

Key works: Economic dislocation, Massive emigration, Ageing, Overall plan, Invigoration. 


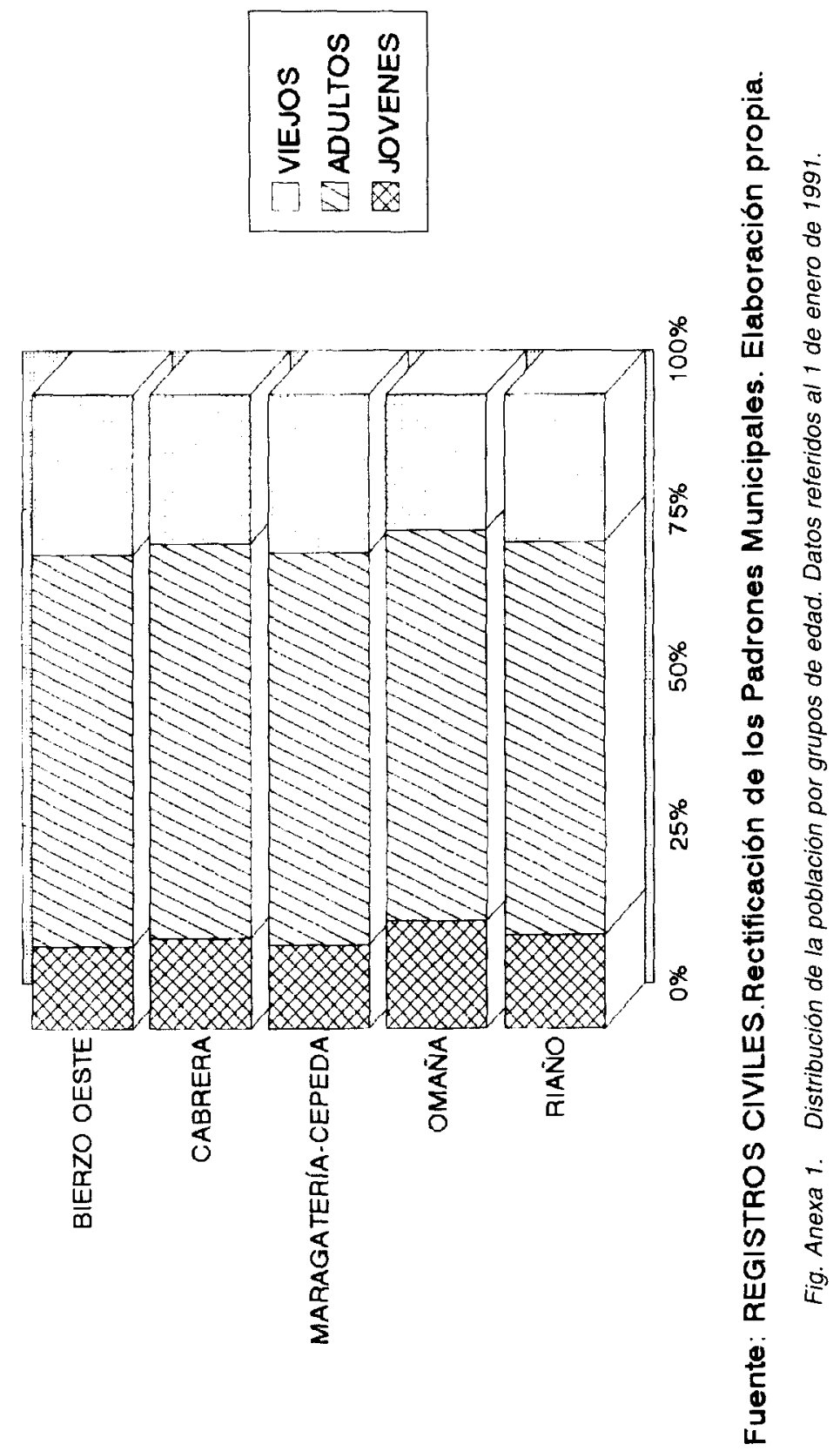




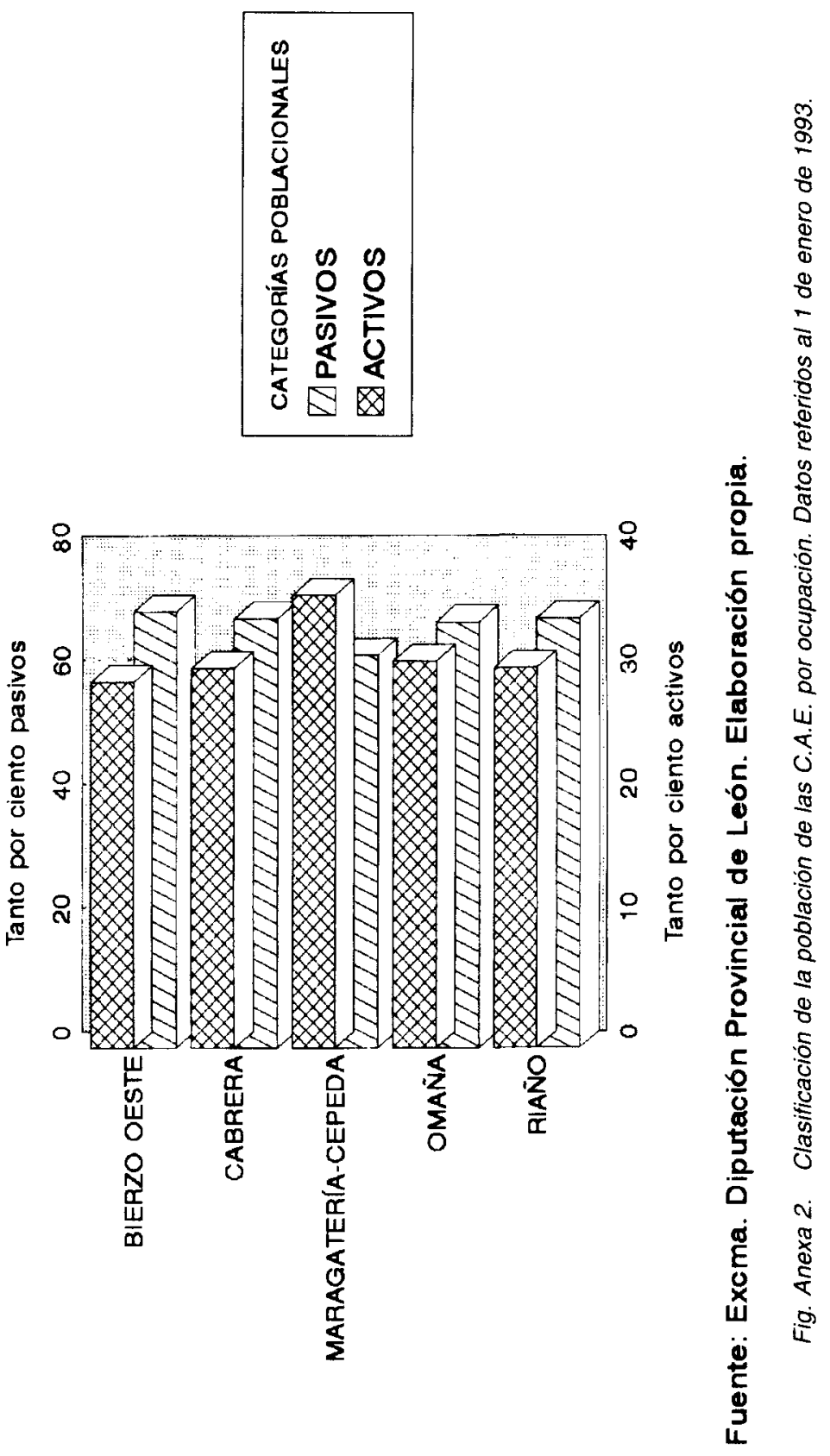




\section{FUENTES}

I.N.E.: Anuarios Estadísticos (1950-1981).

I.N.E.: Censos de población de la provincia de León (desde 1900 hasta 1991).

I.N.E.: Nomenclator de las ciudades, villas, lugares, aldeas y demás entidades de población de la provincia de León (1960-1981).

I.N.E.: Estadística de los Movimientos Naturales de la Población (19601992).

I.N.E.: Censos Agrarios (1962, 1972, 1982).

Ministerio de Agricultura, Pesca y Alimentación: Censos Generales Ganaderos de 1982 y 1986.

Gabinete de Planificación. Excma. Diputación Provincial de León: Encuesta sobre equipamientos e infraestructuras (actualizada al 1 de enero de 1993).

Gabinete de Planificación. Excma. Diputación Provincial de León: Actualización de los Padrones Municipales 1991.

\section{BIBLIOGRAFIA}

Alonso Santos, L., y Cabero Diéguez, V. (1992): Despoblación rural y concentración urbana. Ponferrada, Instituto de Estudios Bercianos.

Astorga GonzÁlez, A. F. (1993): "Aperos, formas y sistemas de cultivo arcaicos en la montaña de León», Tierras de León, no 89-90. Excma. Diputación Provincial de León. 
BECKER, G. (1960): "An economic analisys of fertility". National bureau of economics research demographic and economic change in developed countries. Princeton University Press.

BielzA de Ory, V. (1984): "La población y su distribución espacial», en Geografía General. Madrid. Taurus Ediciones, S.A.

BRAsent, J. (1989): Introduction à l'èconomie du développement. París, A. Colin.

CABERo DiÉguez, V. (1980): Espacio agrario y economía de subsistencia en las montañas galaico-leonesas. La Cabrera. León. Fray Bernardino de Sahagún. C.S.I.C.

CABero DiÉGuez, V. et al. (1987a): "La montaña de Riaño y Cistierna", en La provincia de León y sus comarcas, pp.186-200. León. Diario de León.

(1987b): «Maragatería y Cepeda», en La provincia de León y sus comarcas, pp. 218-230. León. Diario de León.

(1987c): «La Cabrera», en La provincia de León y sus Comarcas, pp. 90104. León. Diario de León.

(1987d): “El Bierzo Alto, El Bierzo Bajo y la montaña Berciana», en La provincia de León y sus comarcas, pp. 26-72. León. Diario de León.

(1988): «Picos de Europa (Valdeón y Sajambre)», en La provincia de León y sus comarcas, pp. 202-216. León. Diario de León.

Caro Baroja, J. (1985): Los pueblos de España. Madrid. Ed. Istmo., vol II.

Cortizo Álvarez, J. (1989): Los asentamientos en la provincia de León: comercio, servicios y jerarquía funcional. León. Universidad de León.

De Miguel, A., y Moral, F. (1984): La población castellana. Valladolid. Ed. Ámbito, S.A.

FERNÁNDEZ, F. (1983): Las Cabreras leonesas. Transformaciones socioeconómicas y ordenación territorial de los 80 . Coloquio Hispano-francés sobre espacios rurales, tomo II, Instituto de Estudios Agrarios, Pesqueros y Alimentarios.

Ferreras Chasco, C. (1981). El norte de la meseta leonesa. León. Fray Bernardino de Sahagún. Excma. Diputación Provincial de León.

García ZARZA, E. (1980): La población de Castilla y León. Burgos. Trabajo Inédito.

Garcia ZaRZA, E.(1983). La emigración en Castilla y León. Consejo General de Castilla y León. Valladolid. Simancas Ed. S.A. 
Crisis y posibilidades de activación socioeconómica de las zonas deprimidas...

GonzÁlez GonzÁlez, Ma. J. et al. (1986): Movimientos migratorios en el norte de León. Madrid. Junta de Castilla y León.

GonzÁlez GonzÁlez, Ma J. (1991): “El envejecimiento actual de la población leonesa», en Poligonos, $n^{0} 1$, págs. 21-40, León.

González Muñoz, C. (1983): Composición de la población mundial. Madrid. Cincel.

González Ramos, J. I., y González Vecin, J. (1991): «El proceso de desarticulación de las bases económicas tradicionales y sus posibles alternativas en los Ancares leoneses", en Polígonos, n¹, págs. 41-65, León.

GONZÁLEZ VECIN, J. (1979): “Causas del subdesarrollo agrícola del Bierzo", en Tierras de León, 34-35, León.

JunTA de CAstilla y LeÓN (1988). Análisis del medio físico: Delimitación de unidades y estructura territorial. León. Valladolid. Junta de Castilla y León. Consejería de Fomento.

López Castellón, E. (coordinador) (1986): Historia de Castilla y León. Madrid. Ediciones Reno, S.A. Vol. X.

LÓPEZ FERNÁNDEZ, B. (1983). “La despoblación leonesa contemporánea». Tierras de León, no 50; págs. 17-33. León.

LóPEZ FernánDEZ, B. (1986): “Atonía y agotamiento en los municipios de la montaña de León, 1976-1980" Ería, ํo10, pp. 130-139.

López Trigal, L. (1979): La red urbana de León. León. Colegio Universitario de León.

LUENGo UGidos, M. A. (1984): Organización ecológica y dinámica del paisaje en los montes de León: El ejemplo de la Cepeda Alta. Departamento de Geografía, Universidad de Salamanca.

Manero, F. (1983): La industria en Castilla y León. Valladolid. Ámbito, S.A.

Ministerio de Agricultura, Pesca y Alimentación (1988): Supervivencia de los espacios naturales. Madrid. Coloquio Hispano-francés sobre espacios naturales. M.A.P.A. Secretaría General Técnica.

Moralejo Mateos, M. P. (1991): «Riaño. significado y perspectivas de un nuevo núcleo de población». Polígonos, no 1, pp. 115-134.

Pressat, R. (1981): Introducción a la demografía. Barcelona. Ariel.

Puyol, R. (1982): Población y espacio. Problemas demográficos mundiales. Cuadernos de Estudio. Madrid. Cincel. 
Sagredo Garcia, J. (1980): Ocaso demográfico de Castilla y León. Exodo burebano. Biblioteca Universitaria Burgalesa. Burgos. Caja de Ahorros Municipal.

STUCKI, E. (1992): Balanced development of the countryside in Western Europe, Strasbourg, Council of Europe Press.

VV.AA. (1988). Geografía de Castilla y León. Valladolid. Ámbito, S.A. Tomo V.

VV.AA. (1989). Geografía de Castilla y León. Valladolid. Ámbito, S.A. TOMO VII.

Veyret-Verner, G. (1959): Population, Grenoble, Arthaud. 